\title{
AERIAL APPLICATION OF INSECTICIDES AND THE SUPPRESSION OF INCIPIENT SPRUCE BUDWORM OUTBREAKS ${ }^{1}$
}

\author{
By J. R. BLAIS ${ }^{2}$
}

\begin{abstract}
The aerial application of insecticides against spruce budworm outbreaks is now a common practice. The measure had always been applied in outbreaks covering more or less extensive areas until 1960 when an opportunity was provided of spraying a small incipient infestation in the Lower St. Lawrence region of the Province of Quebec. It was hoped that early treatment might suppress the infestation and prevent its spread. Although the operation was successful in greatly reducing insect numbers in the area treated, it failed to arrest the infestation. Wind dispersal of first-and second-instar larvae prior to spray application resulted in the spread of the infestation beyond the area delimited for treatment. Also, the warm and dry weather in the spring of 1960, and the abundance of staminate flowers on the balsam fir and spruce trees greatly favoured larval survival. The aerial application of insecticides as a method of suppressing incipient spruce budworm outbreaks is discussed in the light of these results.
\end{abstract}

\section{INTRODUCTION}

The large-scale aerial application of DDT to forests under spruce budworm attack is now an accepted practice. Since 1949, many thousands of square miles of Douglas fir and true fir in western United States, and since 1952, of spruce and balsam fir forests in eastern Canada, have been treated with DDT against the ravages of this insect. Although spraying policies have differed somewhat in the United States and Canada (Webb, 1960), the emphasis has generally been placed on tree protection rather than outbreak suppression. In most instances, only relatively small portions of the infested areas were sprayed in any one year, and the main objective has been to prolong the life of trees through the period of the outbreak. In eastern Canada, where the largest operations have been carried out, treatment was restricted to areas of high hazard where another year's attack would endanger the life of trees. This policy has proved effective and the forest was kept alive in northern New Brunswick and the Gaspé-Lower St. Lawrence regions of Quebec until the time of the outbreak's collapse in 1958 (Webb et al., 1959; Blais and Martineau, 1960).

Usually, spruce budworm outbreaks first appear in localized areas from which they spread until they cover immense territories. It has often been suggested that if these infestation foci could be detected in time and

\footnotetext{
${ }^{1}$ Concribution No. 748, Forest Entomology and Pathology Branch, Department of Forestry, Ottawa, Canada. Cost of publication shared by the Forest Entomology and Pathology Branch and the C.I.F.

siographical reference, For. Chron. 33.
} 
treated with insecticides, widespread outbreaks might be averted. An opportunity of putting this to the test was provided in the Lower St. Lawrence region in the Province of Quebec in 1960.

In the Gaspé-Lower St. Lawrence regions, the outbreak, which began about 1949, had encompassed an area of approximately 14,000 square miles by 1955 . The outbreak started to decline in 1957, and by August of the following year had collapsed over the whole territory, except in a small sector of approximately 30 square miles in the vicinity of Lake Kedgwick (Blais and Martineau, 1960). In 1959, this residual infestation maintained itself and an egg survey was conducted in the fall of that year to determine what populations could be expected in 1960 . The survey was concentrated in or near areas where some defoliation had occurred in 1959, but a number of localities were also sampled some distance away from the area of defoliation (Fig. 1). The survey was carried out according to the sequential sampling technique developed by Morris (1954), which has been used effectively each year since 1954 in connection with the large-scale surveys conducted in New Brunswick and Quebec.

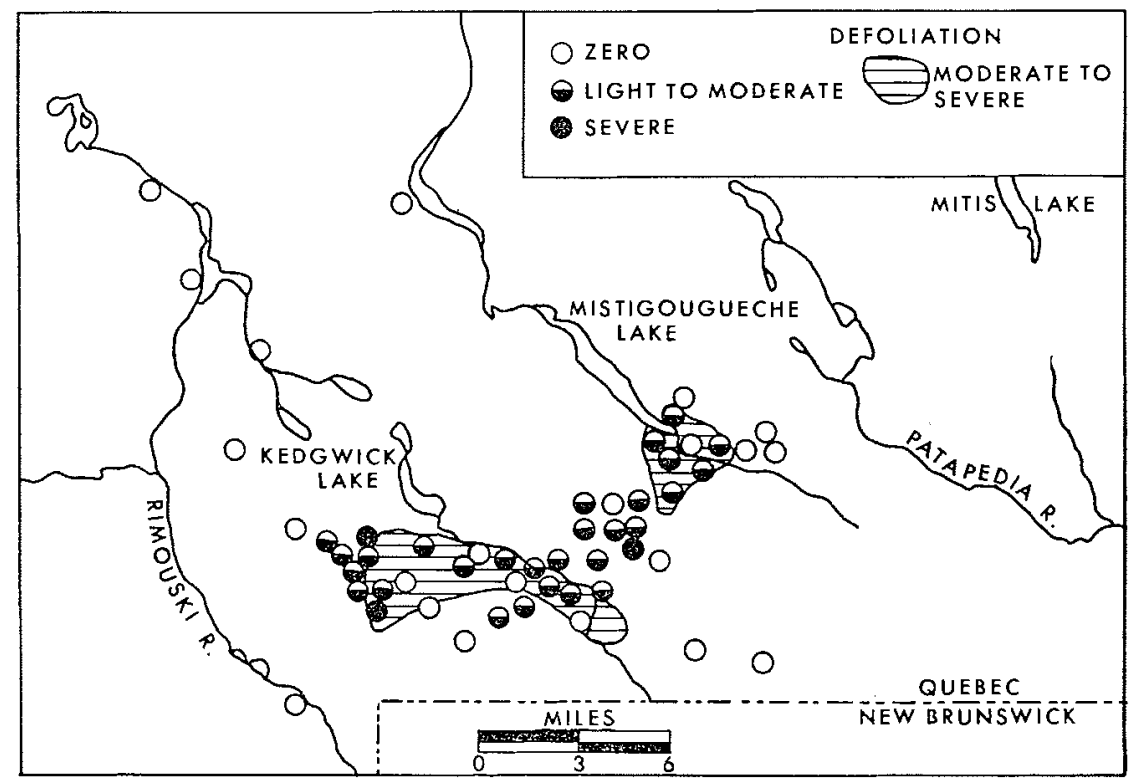

FIGURE 1. Areas of defoliation of the current year's growth, and degree of defoliation expected in 1960 based on egg populations in localities sampled in 1959.

Results of the 1959 survey indicated that generally, spruce budworm populations would be low in the Kedgwick Lake area in 1960 (Table 1). In past years the life of the trees in this area would not have been considered in imminent danger, and treatment would not have been recommended. The situation in 1959, however, was different since this localized infestation could conceivably become the nucleus of a second widespread outbreak. 
TABLE 1

Degree of Defoliation of the 1960 Shoot Growth as Predicted by the

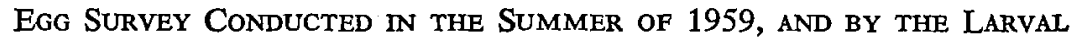

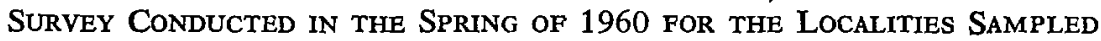

\begin{tabular}{|c|c|c|c|c|c|}
\hline \multirow[b]{2}{*}{ Survey } & \multirow[b]{2}{*}{ Type of area } & \multirow{2}{*}{$\begin{array}{l}\text { No. of } \\
\text { localities } \\
\text { sampled }\end{array}$} & \multicolumn{3}{|c|}{$\begin{array}{c}\text { Percentage of localities for } \\
\text { various degrees } \\
\text { of predicted defoliation }\end{array}$} \\
\hline & & & Severe & $\begin{array}{l}\text { Light to } \\
\text { noderate }\end{array}$ & Nil \\
\hline \multirow[t]{2}{*}{ Eggs, 1959} & $\begin{array}{l}\text { Area originally } \\
\text { recommended for } \\
\text { spraying }\end{array}$ & 35 & 9 & 68 & 23 \\
\hline & $\begin{array}{l}\text { Area outside that } \\
\text { originally recommended } \\
\text { for spraying }\end{array}$ & 18 & 0 & 17 & 83 \\
\hline \multirow[t]{2}{*}{$\begin{array}{l}\text { Larvae, } \\
\text { spring } 1960\end{array}$} & $\begin{array}{l}\text { Area originally } \\
\text { recommended } \\
\text { for spraying }\end{array}$ & 16 & 44 & 56 & 0 \\
\hline & $\begin{array}{l}\text { Area outside that } \\
\text { originally recommended } \\
\text { for spraying }\end{array}$ & 50 & 14 & 58 & 28 \\
\hline
\end{tabular}

For this reason it was planned to spray the 30 square miles of infested area with the object of suppressing this incipient outbreak. All localities outside the area recommended for spraying showed a zero egg count except three which were grouped in an area of less than one square mile immediately adjacent to the area recommended for treatment and in which egg populations were very light.

In the spring of 1960 , population counts were made in 66 localities prior to spraying operations when the larvae were mostly in the third and fourth instars. The sampling points were distributed in an area of approximately 300 square miles, including the area recommended for treatment (Fig. 2). Populations were determined by counting the number of larvae on one 18inch branch tip obtained by means of pole pruners, from the mid-crown of each of five co-dominant balsam fir trees for each locality sampled. When mean populations were lower than 20 per 18 -inch branch tip they were considered as being capable of causing light to moderate defoliation ( 5 to 74 per cent) of the current year's growth; when they were above 20 they were considered sufficiently high to cause severe defoliation ( 75 per cent or more) of the current year's growth.

Results of the sampling showed that populations within the area recommended for treatment were much higher than expected on the basis of the egg survey conducted the previous fall (Table 1). Furthermore, relatively high larval populations were encountered in a large number of localities outside the area recommended for spraying. This infestation which was formerly considered residual and more or less decadent could now be considered as an incipient and virulent outbreak. Although the area to be 
treated was increased by an additional 21 square miles there were still many localities where the insect occurred in outbreak proportions that could not be included at this late date in the current spraying program (Fig. 2). Consequently, treatment of the whole infested area was not achieved.

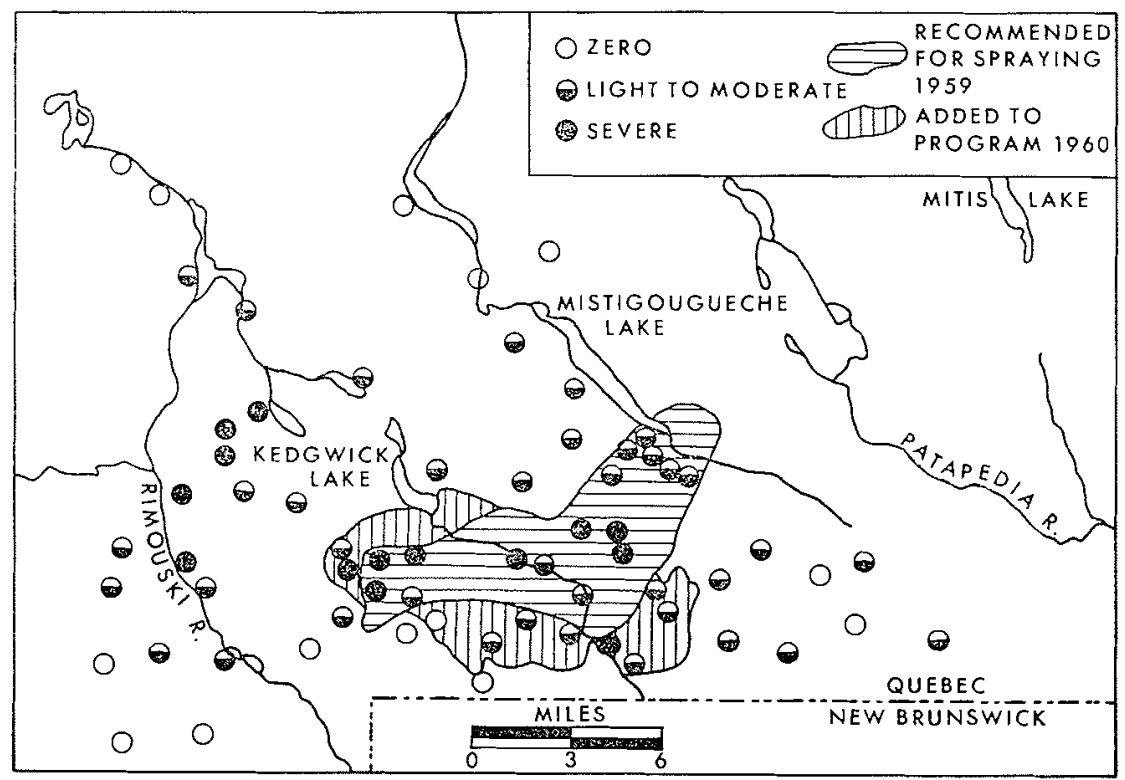

FIGURE 2. Area recommended for spraying, and degree of defoliation expected based on larval populations in localities sampled prior to treatment in the spring of 1960.

A post-spray population survey was conducted at the time when the insect was in the late pupal stage. The same localities were visited and the same methods used as for the pre-spray survey discussed above. In addition, defoliation of the current year's growth was estimated for each branch.

Table 2 shows the average population per 18-inch branch tip for sprayed and unsprayed localities during the pre-spray and post-spray surveys, and the resulting per cent reduction in population. Natural control factors had reduced populations by 62.9 per cent in unsprayed areas, while in sprayed areas the combined effects of natural control and the insecticide had caused a population reduction of 96.2 per cent. Defoliation of the current year's growth was not as extensive in the treated sector as would have been the case had no treatment been applied. In adjacent areas, defoliation was very much as expected on the basis of the larval survey; severe, moderate to light, and nil defoliation was obtained in 15 per cent, 63 per cent, and 22 per cent of the localities sampled. This compares favourably with the predictions shown in Table 1.

A second egg survey was carried out in August 1960. Forty-four localities were sampled, 10 in sprayed territory, and 34 outside (Fig. 3 ). The beneficial 
TABLE 2

Average Population Per 18-Inch Branch Tip for Sprayed and Unsprayed Localities During Early Larval Stage (Pre-Spray) and the Pupal Stage (Post-Spray) and Per Cent Reduction in Population Between THE TWO SURVEYS

\begin{tabular}{|c|c|c|c|c|}
\hline \multirow[b]{2}{*}{ Treatment } & \multirow[b]{2}{*}{$\begin{array}{c}\text { No of } \\
\text { localities }\end{array}$} & \multicolumn{2}{|c|}{$\begin{array}{l}\text { Av. No. of insects per } \\
\text { 18-inch branch }\end{array}$} & \multirow[b]{2}{*}{$\begin{array}{l}\text { Per cent reduction } \\
\text { in population }\end{array}$} \\
\hline & & $\begin{array}{c}\text { Early larval } \\
\text { stage } \\
\text { (pre-spray) }\end{array}$ & $\begin{array}{c}\text { Pupal } \\
\text { stage } \\
\text { (pest-spray) }\end{array}$ & \\
\hline Unsprayed & _.. 40 & 8.9 & 3.3 & 62.9 \\
\hline Sprayed & 27 & 18.2 & 0.7 & 96.2 \\
\hline
\end{tabular}

effects of the sprays were reflected in the low egg populations within the treated area where 70 per cent of the localities sampled gave a zero egg count. Outside of the sprayed area, high egg populations were found in two sectors, one to the east, the other to the west, measuring approximately 40 and 65 square miles respectively. Severe defoliation of the 1961 shoot growth can be expected in these areas. The other localities gave either a zero or a low egg count indicating that defoliation in 1961 would occur in scattered patches of light to moderate defoliation. On the basis of this survey, defoliation of the current year's growth in 1961 should occur in varying degrees within an area of approximately 250 square miles. This represents an increase of 700 per cent of the area infested in 1959.

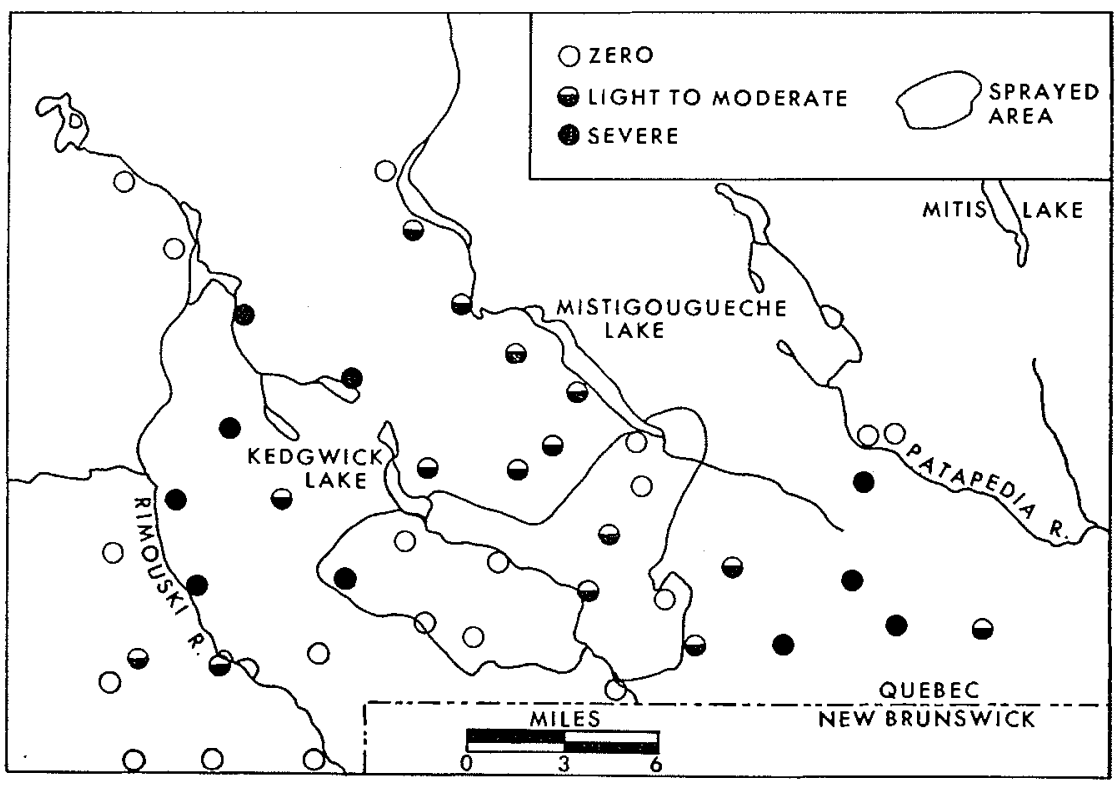

FIGURE 3. Area sprayed, and degree of defoliation expected in 1961 based on egg populations in localities sampled in 1960 . 


\section{Discussion}

Spruce budworm populations in the residual infestation area in the vicinity of Lake Kedgwick were much higher in the spring of 1960 than was expected on the basis of the egg survey carried out the previous summer. A poorly conducted egg-survey could be a possible explanation for such a situation, but, in the present case, this argument hardly applies since the survey was carried out by competent personnel with several years of experience in such work.

It is felt that the disparity between the outbreak boundaries as predicted in 1959, and the actual extent of the outbreak in the spring of 1960 was the result of two main factors: unusually favourable conditions for spruce budworm survival, and wind-dispersal of first- and second-instar larvae from the focus of the infestation.

The first of these factors was attributable to the combined influence of propitious weather and food conditions. The weather in May and June was exceptionally dry and warm. It has been shown that periods of low precipitation in late spring and early summer are especially favourable to the spruce budworm (Wellington et al., 1950; Greenbank, 1956; Pilon and Blais, 1961). Furthermore, there was an unusual abundance of staminate flowers on balsam fir and on white and black spruce in the spring of 1960 . These flowers offer food and shelter conditions particularly favourable to larval development and survival (Blais, 1952; 1957). As a result, populations that normally should have been light to moderate were, in effect, moderate to severe.

Insect numbers were not only higher than predicted in the area recommended for spraying, but occurred in outbreak proportions outside of this area where none had been expected. This undoubtedly resulted, in part, from the exceptionally high survival of local populations that were too low to be measured by the sampling method used in the fall of 1959. However, this explanation cannot account for the great abundance of larvae found in the spring of 1960 in certain localities; for instance, in one locality near Deschênes Lake where no eggs were found in 1959, there was an average of 52 larvae per 18-inch branch tip in the spring of 1960. Situations such as this could be found at a distance of six to seven miles from the periphery of the 1959 outbreak area (Fig. 2). It is known that wind dispersal of small larvae on emergence from the egg in summer and from the hibernacula in the spring can be extensive (Blais, 1952). At such times, the minute larvae often hang from silk threads and can be transported long distances by air currents. It is probable that a large number of the insects occurring outside of the outbreak area delimited in 1959 resulted from such wind-dispersal. The propitious survival conditions discussed above also favoured the establishment of these transported larvae in the newly invaded localities.

The combined influence of favourable weather and food conditions that permitted such high larval survival in the spring of 1960 was an unusual situation that could be expected to recur only at long intervals. Population spread through wind dispersal of small larvae is, however, a more common occurrence. In the treatment of outbreaks where the main objective is tree pro- 
tection, this dispersal does not greatly influence the outcome of the operations, but in the case of incipient infestations where suppression is the main objective, spread through larval dispersal is of much greater importance. An egg survey remains the only practical means whereby the distribution of the following year's populations can be assessed. If, however, there is large-scale larval dispersal after egg counts have been made and before the trees are sprayed, it becomes difficult to predict the areas of infestation that will require treatment.

Thus, although the 1960 spraying operation was successful in greatly reducing spruce budworm populations in the area treated, it failed to suppress the outbreak. This failure was partially attributable to the inability of predicting in 1959 the extent of the outbreak in 1960. An aerial-spraying program requires many months of peparation, and these must be made in conjunction with specific areas to be treated. Although some last minute changes can be made with respect to the areas requiring treatment, these changes must of necessity be very limited. In the case of the project under discussion, 21 square miles were added to the spray area a few days prior to the commencement of operations. This was possible because a large-scale operation was concurrently taking place in central New Brunswick. Had the project in the Lower St. Lawrence region been completely isolated, such an increase in the area to be treated would not have been feasible.

Even should the whole of an outbreak area be treated, there is no assurance that the measure would be successful in bringing the outbreak to an end. Although a high percentage of the population is usually killed by spraying (Webb, 1958; Blais and Martineau, 1960) there is always a residual population that, under favourable conditions, might attain very high numbers in two to three years. In addition to spraying the entire infested area, success in suppressing an incipient spruce budworm outbreak could very well depend on insect survival conditions during the year of treatment and the one or two years immediately following. The reduction in population brought about by natural control factors, although not necessarily sufficient to cause an outbreak to collapse, could conceivably bring about the suppression of populations already greatly reduced through chemical treatment. Favourable survival conditions, on the other hand, could permit a recrudescence of residual populations in treated areas.

The suppression of incipient spruce budworm infestations through the aerial application of insecticides will always be difficult to achieve, but such undertakings need not necessarily be destined to failure. Further studies are needed to produce additional information necessary in the solution of this problem.

\section{ACKNOWLEDGEMENTS}

The Department of Lands and Forests of the Province of Quebec furnished personnel and transportation facilities for some of the field work. Thanks are due to Price Brothers and Company Limited who provided living quarters at their Lake Rimouski Depot in the fall of 1959 and the summer of 1960. Dr. René Pomerleau, Dr. R. J. Finnegan, and Dr. J. M. McLeod, of the Quebec forest Biology Laboratory, kindly reviewed the manuscript. 


\section{REFERENCES}

BLAIS, J. R. 1952. The relationship of the spruce budworm (Cboristoneura fumiferana, Clem.) to the flowering condition of balsam fir (Abies balsamea (L) Mill.) Can. J. Zool. 30: 1-29.

BLAIS, J. R. 1957. Some relationships of the spruce budworm to black spruce. For. Chron. 33: $364-372$

BLAIS, J. R. and R. MARTINEAU, 1960. A recent spruce budworm outbreak in the Lower St. Lawrence and Gaspé Peninsula with reference to aerial spraying operations. For. Chron. 36: 209-224.

GREENBANK, D. O. 1956. The role of climate and dispersal in the initiation of outbreaks of the spruce budworm in New Brunswick. I. The role of climate. Can. J. Zool. 34: $453-476$.

MORRIS, R. F. 1954. A sequential sampling technique for spruce budworm egg surveys. Can. J. Zool. 32: 302-313.

PILON, J. G, and J. R. BLAIS, 1961. Weather and outbreaks of the spruce budworm in the Province of Quebec from 1939 to 1956. Can. Ent. 93: 118-123.

WEBB, F. E. 1958. Biological assessment of aerial forest spraying against the spruce budworm in New Brunswick. II. A review of the period 1952-1956. Proc. Tenth Int. Congr. Ent., 1956, 4: 525-531.

WEBB, F. E ., MACDONALD, D. R. and D. G. CAMERON, 1959. Aerial spraying against spruce budworm in New Brunswick-1958. Bi-Mon. Prog. Rept. Div. For. Biol,, Dept. Agr. Can., 15(1): 1-2.

WEBB, F. E. 1960. Aerial forest spraying against spruce budworm-A problem of mutual interest in Canada and the United States. J. Econ. Ent. 53: 631-633.

WELLINGTON, W. G., FETTES, J. J., TURNER, K. B. and R. M. BELYEA, 1950. Physical and biological indicators of the development of outbreaks of the spruce budworm Choristoneura fumiferana (Clem.) (Lepidoptera: Tortricidae). Can. J. Res. D. 28: 308-331. 